\title{
OPERATIONAL CHARACTERISTICS OF AERATED AGITATED VESSELS UNDER MECHANICAL FOAM CONTROL
}

\author{
Masami YASUKAWA, MaSaYuki ONODERA, KazUaKi YAMAGIWA \\ AND AKIRA OHKAWA \\ Department of Material and Chemical Engineering, Niigata University, \\ Niigata 950-21
}

\begin{abstract}
Key Words: Aerated Agitated Vessel, Mechanical Foam-Breaking, Agitation Power, Gas Holdup, Antifoam Agent
\end{abstract}

The mechanical foam-control method is free of problems when foaming is controlled by antifoam agents $(\mathrm{AFs}){ }^{2,3,6)}$ In addition, its application to the aerated agitated vessel (AAV) allows substantial reduction of agitation power compared to the AAV including an $\mathrm{AF}$, due to the increased gas holdup. ${ }^{4}$ The performance characteristics of the AAV with a rotating disk foam-breaker (MFRD) were demonstrated in a previous paper. ${ }^{5)}$ The main objective of the present note is to investigate the operational characteristics of AAVs with MFRDs of different sizes.

\section{Experimental}

Two AAVs with vessels diameter $D_{T}$ of 0.19 and

Received January 10, 1990. Correspondence concerning this article should be addressed to A. Ohkawa.
$0.27 \mathrm{~m}$ were used. They were geometrically similar to the AAV of $D_{T}=0.23 \mathrm{~m}^{4,5)}$ A six-blade turbine $\left(D_{i}=D_{T} / 3, \quad b=D_{i} / 5, \quad l=D_{i} / 2.86\right.$ and $d_{i}=D_{i} / 1.3$ in dimensions) was used for each AAV. For air sparging, two ring spargers $\left(D_{T} / 3\right.$ in diameter) with seven and seventeen holes respectively of $1.0 \times 10^{-3} \mathrm{~m}$ diameter were used for AAVs of $D_{T}=0.19$ and $0.27 \mathrm{~m}$. The impeller and liquid depth were held at $D_{T} / 3$ and $D_{T}$. For additional details of this type of AAV, refer to the previous papers. ${ }^{4,5)}$ The gas superficial velocity $V_{s}$ ranged from $3.79 \times 10^{-3}$ to $7.58 \times 10^{-3} \mathrm{~m} / \mathrm{s}$. The MFRD was set at a height of $2.0 D_{T}$ from the bottom. As the rotating disk, two disks, 0.1487 and $0.2114 \mathrm{~m}$ in diameter $D_{d}$, were employed for AAVs of $D_{T}=0.19$ and $0.27 \mathrm{~m}$ respectively. The ratio of $D_{T}$ to $D_{d}$ in the two AAVs was approximately equal to $1.28^{4,5)}$ in the AAV of $D_{T}=0.23 \mathrm{~m}$. The liquid feed rate $W$ onto the 
rotating disk was varied from $1.0 \times 10^{-5}$ to $3.0 \times 10^{-5}$ $\mathrm{m}^{3} / \mathrm{s}$. Critical disk rotational speed required for foam-breaking, liquid holdup in foam, agitation power and gas holdup were measured according to the respective methods employed in the previous work. ${ }^{5)}$ Table 1 shows the properties of foaming and non-foaming liquids used at $293 \mathrm{~K}$.

\section{Results and Discussion}

2.1 Foam-breaking characteristics of the MFRD in terms of changes in the required disk rotational speed

The change in critical disk rotational speed $N_{c}$ was measured for each AAV at a transient state, which is in the regime of foam-breaking to non-foam-breaking as a critical foam-breaking state. ${ }^{4)}$ The effects of $W$ and $V_{s}$ on $N_{c}$ were similar to those observed previously. ${ }^{5}$ ) That is, the smaller is $W$ and the larger is $V_{s}$, the higher $N_{c}$ becomes. The typical relationship between $N_{c}$ and $R e_{i}$ is shown in Fig. 1(a), together with the results in the AAV of $D_{T}=0.23 \mathrm{~m}$ and $D_{d}=0.1800 \mathrm{~m} .{ }^{5)} N_{c}$ values tended to be high in the AAV of small $D_{T}$. As to the Reynolds numbers $\left(R e_{i}\right)_{1}$, at which $N_{c}$ begins to decrease, and $\left(R e_{i}\right)_{2}$, above which $N_{c}$ is almost free from the effect of $R e_{i}$, there was little difference in value due to those of $D_{T}$.

For the data observed when $W$ was varied within the range below $W_{t}$ values which could be predicted by Eq. (1), ${ }^{5)}$ the correlations of $N_{c}$ with the operating variables were then carried out.

$$
N_{w}^{+}=0.441\left(N_{R e}\right)^{2 / 3}\left(N_{W e}\right)^{-0.883}
$$

Equation (1) indicates the transition boundary at which the pattern of liquid disintegration by a rotating disk changes from the region of ligament formation effective for foam-breaking to the region of liquid film formation which is ineffective for foam-breaking. In the same manner as in the previous work, ${ }^{5)}$ the $N_{c}$ values expressed in the form of the peripheral velocity $N_{c} D_{d}$ of the disk were found to be correlated by the following form within $10 \%$ error.

$$
N_{c} D_{d}=A(Q / W)^{0.22}\left(R e_{i}\right)^{B}
$$

Equation (2) is applicable when $D_{T}$ is $0.19-0.27 \mathrm{~m}$, $D_{T} / D_{d}$ ratio is $1.28, Q$ is $1.07 \times 10^{-4}-4.34 \times 10^{-4} \mathrm{~m}^{3} / \mathrm{s}$, $W$ is $1.0 \times 10^{-5}-W_{t} \mathrm{~m}^{3} / \mathrm{s}$ and $R e_{i}$ is $3.0 \times 10^{4}-2.0 \times 10^{5}$. The values of empirical constants $A$ and $B$ in Eq. (2) which change according to the range of $R e_{i}$ and the liquid are summarized in Table 2.

2.2 Foaming behaviour in AAVs and foam-breaking behaviour of the MFRD in terms of changes in liquid holdup in foam

The relationship between the liquid holdup in foam, $\phi_{L}$, measured at the same operating conditions as in Fig. 1(a), and $R e_{i}$ is shown in Fig. 1(b). It is found from a comparison between Figs. 1(a) and 1(b) that the change in $\phi_{L}$ with $R e_{i}$ is very similar to that in

\begin{tabular}{|c|c|c|c|c|}
\hline Liquid & $\begin{array}{c}C_{F} \\
{[p p m]}\end{array}$ & $\begin{array}{c}\rho \\
{\left[\mathrm{kg} / \mathrm{m}^{3}\right]}\end{array}$ & $\begin{array}{l}\mu \times 10^{3} \\
{[\mathrm{~Pa} \cdot \mathrm{s}]}\end{array}$ & $\begin{array}{l}\sigma \times 10^{3} \\
{[\mathrm{~N} / \mathrm{m}]}\end{array}$ \\
\hline $\mathrm{F}^{1)}-\mathrm{D}^{*}$ & - & 998.2 & 1.00 & 53.94 \\
\hline $\mathrm{F}^{1)}-\mathrm{E}^{* *}$ & - & 999.4 & 1.06 & 51.06 \\
\hline $\mathrm{F}^{2)}-\mathrm{S}^{* * *}$ & - & 1000.3 & 1.13 & 50.57 \\
\hline \multirow[t]{4}{*}{$\mathrm{NF}^{2)}-\mathrm{D}^{*}$} & $570^{+}$ & 998.2 & 1.00 & 39.05 \\
\hline & $11140^{+}$ & 998.2 & 1.01 & 38.88 \\
\hline & $640^{+\dagger}$ & 998.2 & 1.01 & 29.17 \\
\hline & $1280^{\dagger \dagger}$ & 998.3 & 1.02 & 28.97 \\
\hline \multirow[t]{4}{*}{$\mathrm{NF}^{2)}-\mathrm{E}^{* *}$} & $741^{\dagger}$ & 999.6 & 1.04 & 39.31 \\
\hline & $1482^{\dagger}$ & 999.8 & 1.05 & 35.78 \\
\hline & $159^{\dagger+\dagger}$ & 999.6 & 1.04 & 36.20 \\
\hline & $318^{+\dagger \dagger}$ & 999.7 & 1.05 & 35.66 \\
\hline \multirow[t]{4}{*}{$\mathrm{NF}^{2)}-\mathrm{S} * * *$} & $60^{\dagger}$ & 1000.3 & 1.13 & 41.71 \\
\hline & $120^{+}$ & 1000.4 & 1.13 & 40.60 \\
\hline & $127^{+++\dagger}$ & 1000.4 & 1.13 & 32.79 \\
\hline & $254^{\dagger++\dagger}$ & 1000.4 & 1.14 & 30.03 \\
\hline
\end{tabular}

Table 1. Properties of liquids

${ }^{1)} \mathrm{F}$; foaming, ${ }^{2)} \mathrm{NF}$; non-foaming.

$* 10^{-2}$ vol\% detergent (Lipon F, Lion Corp.), $* * 5.0 \times 10^{-1}$ $\mathrm{wt} \%$ egg albumin, ${ }^{* * *} 2.0 \mathrm{wt} \%$ soybean meal (liquid filtered after one hours' boiling), ${ }^{\dagger} \mathrm{KM}-70$, silicon oil (Shin-Etsu Chemical Co. Ltd.). ${ }^{\dagger \dagger}$ BF-7, ${ }^{\dagger+} \mathrm{CC}-118,{ }^{++\dagger}$ BF-75, Nissan Disfoam (Nihon Yushi Corp.).

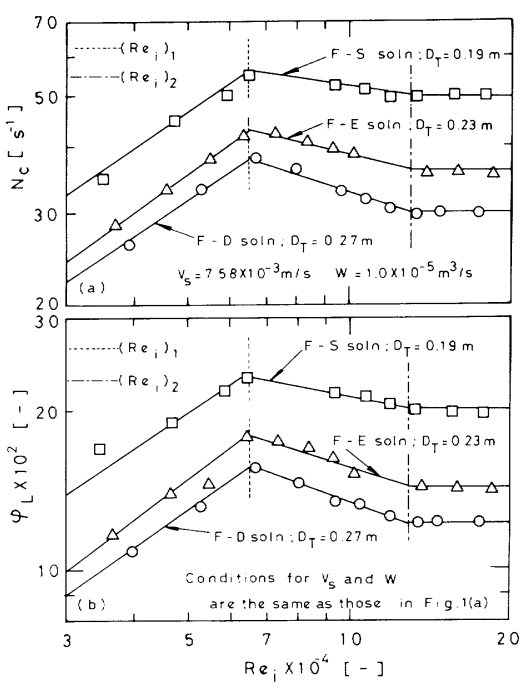

Fig. 1. (a), Relationship between $N_{c}$ and $R e_{i}$; (b), Relationship between $\phi_{L}$ and $R e_{i}$

$N_{c}$. Good correspondence between the change in $N_{c}$ and $\phi_{L}$ with $V_{s}$ was also observed. These results show that $\phi_{L}$ is not only a typical measure reflecting foaming behavior in AAVs but also a measure related to hardness or ease of mechanical foam-breaking in terms of required disk speed.

2.3 Relationship between power consumption for foam-breaking and $\phi_{L}$

The power consumption for foam-breaking, i.e., the power $P_{K c}$ required for liquid dispersion by the rotating disk, was calculated from Eq. $(3)^{5)}$ by using the measured values of $N_{c}$. 
Table 2. Values of A and B in Eq. (2)

\begin{tabular}{cccc}
\hline Liquid & $\begin{array}{c}R e_{i} \\
{[-]}\end{array}$ & $\begin{array}{c}A \\
{[\mathrm{~m} / \mathrm{s}]}\end{array}$ & $\begin{array}{c}B \\
{[-]}\end{array}$ \\
\hline \multirow{3}{*}{ F-D* } & $3.5 \times 10^{4}-6.5 \times 10^{4}$ & $2.57 \times 10^{-3}$ & 0.64 \\
& $6.5 \times 10^{4}-1.3 \times 10^{5}$ & $1.69 \times 10^{2}$ & -0.36 \\
& $1.3 \times 10^{5}-2.0 \times 10^{5}$ & 2.41 & 0 \\
& & & \\
F-E** & $3.5 \times 10^{4}-6.5 \times 10^{4}$ & $1.72 \times 10^{-3}$ & 0.69 \\
& $6.5 \times 10^{4}-1.3 \times 10^{5}$ & 42.2 & -0.22 \\
& $1.3 \times 10^{5}-2.0 \times 10^{5}$ & 3.09 & 0 \\
F-S*** & $3.5 \times 10^{4}-6.5 \times 10^{4}$ & $1.66 \times 10^{-3}$ & 0.71 \\
& $6.5 \times 10^{4}-1.3 \times 10^{5}$ & 28.6 & -0.17 \\
& $1.3 \times 10^{5}-2.0 \times 10^{5}$ & 3.86 & 0 \\
\hline
\end{tabular}

$$
N_{P K}=4.29\left(N_{W}\right)^{1.0}\left(N_{R e}\right)^{0.02}\left(N_{W e}\right)^{0.06}
$$

Equation (3) is applicable when $N_{W}$ is $5.6 \times 10^{-6}$ $1.2 \times 10^{-3}, N_{R e}$ is $5.9 \times 10^{4}-3.4 \times 10^{6}$ and $N_{W e}$ is $1.5 \times 10^{3}-1.2 \times 10^{6}$. The typical relationship between $P_{K c}$ and $\phi_{L}$ for each AAV is shown in Fig. 2, in which the data ${ }^{5)}$ in the AAV of $D_{T}=0.23 \mathrm{~m}$ are also plotted. On the whole, good correspondence is seen between the increases in $P_{K c}$ and $\phi_{L}$, indicating that a foam of larger $\phi_{L}$ requires more power for foam-breaking. This result suggests that the value of $\phi_{L}$ can also be related to hardness or ease of mechanical foam-breaking in terms of power for foam-breaking. Moreover, regarding the fact that $P_{K c}$ values tend to be high in the large $\mathrm{AAV}$, the main cause seems to be related to the increased dispersion distance of the liquid particles from the disk due to the increase of $D_{T}$ and the increased frequency of impact between the dispersed liquid particles and the ascending foam.

\subsection{Agitation power}

For ungassed foaming liquids, the power number $N_{P 0}$ was measured for each AAV, All the systems had the tendency that $N_{P 0}$ decreased when $R e_{i}$ exceeded about $7.4 \times 10^{4}$, due to the effect of air entrainment from the free liquid surface. ${ }^{5}$ ) The $N_{P 0}$ values at $R e_{i}$ below $7.4 \times 10^{4}$ were $4.9,5.1$ and 5.8 for AAVs of $D_{T}=0.19,0.23$ and $0.27 \mathrm{~m}$ respectively, which agreed with those estimated from the correlation proposed by Bujalski et al., ${ }^{1)}$ within $5 \%$ error. The $N_{P 0}$ values at $R e_{i}$ above $7.4 \times 10^{4}$ were expressed by the following form within $10 \%$ error.

$$
\begin{aligned}
& N_{P 0}=R e_{i}^{-3.95 \times 10^{-5} D_{T}^{-6.40}} e^{f\left(D_{T}\right)} \\
& f\left(D_{T}\right)=10^{4.03-14.69 D_{T}}+2.532
\end{aligned}
$$

The agitation power $P_{g f}$ in a mechanical foam-control system (MFS) and the agitation power $P_{g}$ in a non-foaming system (NS) including AFs were then measured. $P_{g f}$ was little affected by $W$. There were no significant differences in $P_{g}$ when the kind and quantity of AF were varied. Figure 3 shows typical results of $P_{g f} / P_{g}$ at $W$ ranging from $1.0 \times 10^{-5}$ to $3.0 \times 10^{-5}$

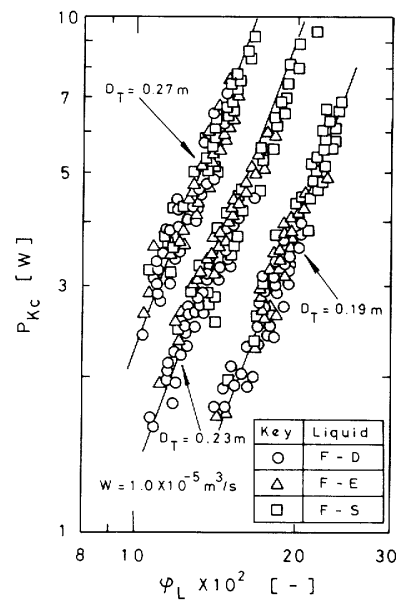

Fig. 2. Relationship between $\phi_{L}$ and $P_{K c}$

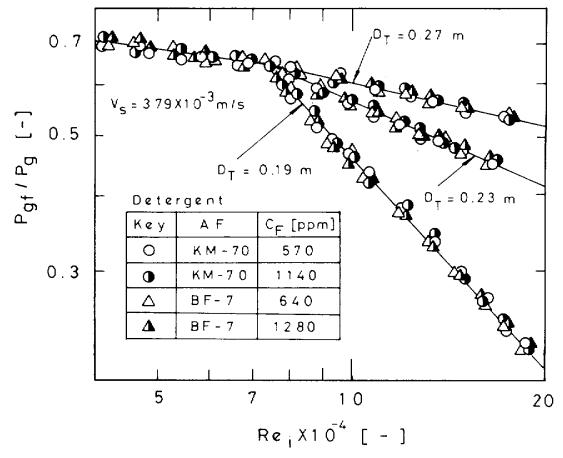

Fig. 3. Change of $P_{g f} / P_{g}$ with $R e_{i}$

$\mathrm{m}^{3} / \mathrm{s}$ plotted against $R e_{i}$. In all the systems, $P_{g f} / P_{g}$ values at the same aeration-agitation rate conditions were below 1.0. The $P_{g f}$ values were correlated by the following equation, obtained in the previous work, ${ }^{5)}$ within $10 \%$ error regardless of $D_{T}$.

$$
P_{g f}=7.40 \times 10^{-1}\left(P_{0}^{2} N_{i} D_{i}^{3} / Q^{0.56}\right)^{0.43}
$$

\subsection{Gas holdup}

The gas holdups based on dispersion volume, $\varepsilon_{g f}$ and $\varepsilon_{g}$, in the MFS and the NS were measured. $\varepsilon_{g f}$ values, which were almost free from the effect of $W$ in the range between $1.0 \times 10^{-5}$ and $3.0 \times 10^{-5} \mathrm{~m}^{3} / \mathrm{s}$, were large compared to $\varepsilon_{g}$ values. That is, as shown in an example of Fig. 4, the values of the gas holdup ratio $\varepsilon_{g f} / \varepsilon_{g}$ were larger than 1.0. Moreover, there were few effects of the kind and quantity of AF on $\varepsilon_{g}$ in each AAV. For the correlations of gas holdup $\varepsilon_{g f}$, the effect of $V_{s}$ on $\varepsilon_{g f} /\left(1-\varepsilon_{g f}\right)^{2}$ was almost the same as that $^{5)}$ observed in the AAV of $D_{T}=0.23 \mathrm{~m}$. In the same manner as in the change of $N_{c} D_{d}$ in Fig. 1(a), the increases of $\varepsilon_{g f} /\left(1-\varepsilon_{g f}\right)^{2}$ with $R e_{i}$ were also found to be divided into three regions by two transition $R e_{i} S$, as shown in Table 2. The effect of power input per unit volume $P_{g f} / V_{L}$ on $\varepsilon_{g f} /\left(1-\varepsilon_{g f}\right)^{2}$ was then examined. As a result, Eqs. (8a)-(8c) were obtained within $15 \%$ error regardless of $D_{T}$. 


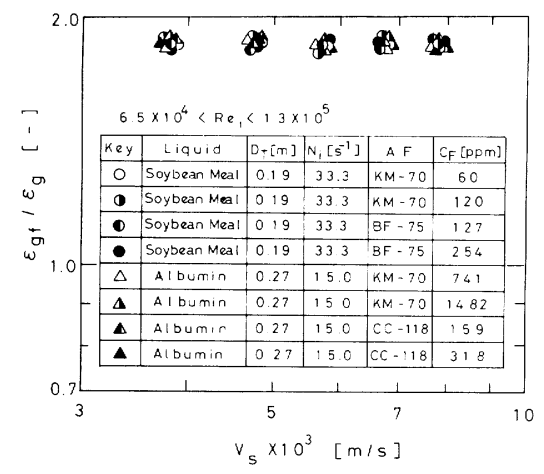

Fig. 4. Change of $\varepsilon_{g f} / \varepsilon_{g}$ with $V_{s}$

$$
\begin{aligned}
3.0 \times 10^{4}<R e_{i} & \leqq 6.5 \times 4 \\
\varepsilon_{g f} /\left(1-\varepsilon_{g f}\right)^{2} & =a V_{s}^{0.75}\left(P_{g f} / V_{L}\right)^{1.00} \\
6.5 \times 10^{4}<R e_{i} & \leqq 1.3 \times 10^{5} \\
\varepsilon_{g f} /\left(1-\varepsilon_{g f}\right)^{2} & =b V_{s}^{0.34}\left(P_{g f} / V_{L}\right)^{0.66} \\
1.3 \times 10^{5}<R e_{i} & \leqq 2.0 \times 10^{5} \\
\varepsilon_{g f} /\left(1-\varepsilon_{g f}\right)^{2} & =c V_{s}^{0.22}\left(P_{g f} / V_{L}\right)^{0.25}
\end{aligned}
$$

where $a, b$ and $c$ are empirical constants. The values of a were $1.14 \times 10^{-2}, 1.24 \times 10^{-2}$ and $1.90 \times 10^{-2}$, respectively; those of $b 1.28 \times 10^{-2}, 1.37 \times 10^{-2}$ and $2.89 \times 10^{-2}$, respectively; and those of $c 2.32 \times 10^{-1}$, $2.41 \times 10^{-1}$ and $6.15 \times 10^{-1}$, respectively for F-D, F-E and F-S solutions.

\subsection{Application of the MFRD to a large AAV}

Estimation of characteristics values such as $N_{c}$ and $P_{K c}$ in a MFRD fitted in a larger AAV than those used in this work was attempted. The dimensions of a large AAV having the same geometrical design as that of the AAV used in the present work (the vessel, the rotating disk, the impeller, etc.) were first determined. For the large AAV with the MFRD having the dimensions determined, $N_{c}$ and $P_{K c}$ values were then calculated with Eqs. (2) and (3), respectively, assuming that correlation equations can be also used for the large AAV.

The results of $N_{c}$ and $P_{K c}$ for the large AAV when $D_{T}$ is scaled up to $5.0 \times 10^{-1} \mathrm{~m}$ and a disk of $D_{T} / D_{d}=1.28$ is employed for F-D solution at $V_{s}$ ranging from $8.32 \times 10^{-3}$ to $1.66 \times 10^{-2} \mathrm{~m} / \mathrm{s}$, corresponding to 1.0 to $2.0 \mathrm{vvm}$, and at $R e_{i}$ above $1.3 \times 10^{5}$ corresponding to $4.7 \mathrm{rps}$, which is the region where $N_{c}$ is almost free from the effect of $R e_{i}$, are shown in Fig. 5. The dotted line in Fig. 5(a) represents Eq. (1) for a disk of $D_{d}=0.39 \mathrm{~m}$, that is, the boundary above which the reduction of $N_{c}$ caused by the increase of $W$ begins to level off. In Fig. 5(a), the oblique-lined areas enclosed with the curve drawn by Eq. (1) and the $N_{c}-W$ curves drawn by Eq. (2) are the operational range under which foaming can be controlled effectively and economically with the MFRD. For a more accurate scaleup of the MFRD fitted to the

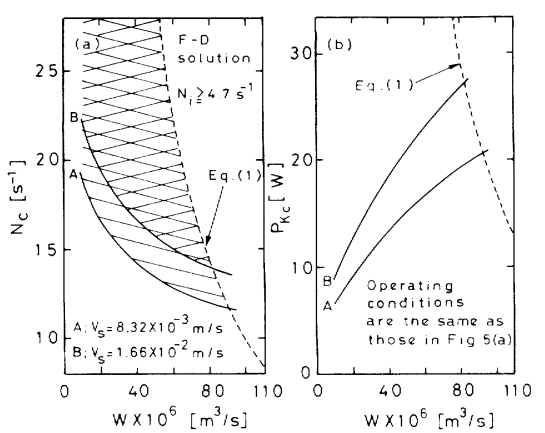

Fig. 5. (a), Characteristic curve of $N_{c}$ in large MFRD; (b), Characteristic curve of $P_{K c}$

AVV, although further information concerning the oxygen transfer rate will be necessary, the estimation method demonstrated here may be used to predict the performance and effective operational range of a MFRD fitted into the larger AAV.

\section{Nomenclature}

$b \quad=$ impeller blade width $[\mathrm{m}]$

$C_{F} \quad=$ concentration of antifoam agent $\quad[\mathrm{ppm}]$

$\begin{array}{lll}D_{d} & =\text { rotating disk diameter }\end{array}$

$D_{i} \quad=$ impeller diameter $\quad[\mathrm{m}]$

$D_{T} \quad=$ vessel diameter $\quad[\mathrm{m}]$

$d_{i} \quad=$ impeller disk diameter $\quad[\mathrm{m}]$

$l \quad=$ impeller blade length $\quad[\mathrm{m}]$

$N \quad=$ rotating disk speed $\quad[1 / \mathrm{s}]$

$N_{c} \quad=$ rotating disk speed required at the critical foam-breaking state

$=$ impeller rotational speed

$=$ flow number $\left(=W / N D_{d}^{3}\right)$

$=$ dimensionless transition liquid feed rate from ligament to filmy formation $\left(=W_{t} / D_{d}^{2} \sqrt{v N}\right) \quad[-]$

$=$ power number $\left(=P_{K} / \rho N^{3} D_{d}^{5}\right)$

$=$ power number $\left(=P_{0} / \rho N_{i}^{3} D_{i}^{5}\right)$

$=$ Reynolds number $\left(\rho N D_{d}^{2} / \mu\right)$

$=$ Weber number $\left(=\rho N^{2} D_{d}^{3} / \sigma\right) \quad[-]$

$=$ agitation power in ungassed liquid $\quad[\mathrm{W}]$

$=$ agitation power in gassed liquid [W]

$=$ power consumption for foam-breaking (= power for liquid dispersion by rotating disk)

$P_{K c} \quad=$ power consumption for foam-breaking at the critical state

$Q$

$=$ volumetric gas sparge rate

$\left[\mathrm{m}^{3} / \mathrm{s}\right]$

$=$ Reynolds number $\left(=\rho N_{i} D_{i}^{2} / \mu\right)$

$[-]$

$=$ working volume

$\left[\mathrm{m}^{3}\right]$

$=$ gas superficial velocity

$[\mathrm{m} / \mathrm{s}]$

$V_{s}$

$v v m$

$W$

$=$ volumetric air flow per minute per working volume

$[1 / \mathrm{min}]$

$=$ liquid feed rate onto the disk $\quad\left[\mathrm{m}^{3} / \mathrm{s}\right]$

$=$ transition liquid feed rate from ligament to filmy formation, calculated by Eq. (1) $\quad\left[\mathrm{m}^{3} / \mathrm{s}\right]$

$\varepsilon_{g} \quad=$ gas holdup based on dispersion volume $\quad[-]$

$\mu \quad=$ viscosity of liquid $[\mathrm{Pa} \cdot \mathrm{s}]$

$v \quad=$ kinematic viscosity of liquid $\quad\left[\mathrm{m}^{2} / \mathrm{s}\right]$

$=$ density of liquid $\left[\mathrm{kg} / \mathrm{m}^{3}\right]$

$=$ surface tension of liquid $\quad[\mathrm{N} / \mathrm{m}]$

$=$ liquid holdup in foam $\quad[-]$ 
$\langle$ Subscripts〉

$f \quad=$ mechanical foam-controlling system

$1=$ transition point on $R e_{i}$ at which $N_{c}$ begins to decrease

$2=$ transition point on $R e_{i}$ from which $N_{c}$ becomes constant

\section{Literature Cited}

1) Bujalski, W., A. W. Nienow, S. Chatwin and M. Cooke: Chem. Eng. Sci., 42, 317 (1987).
2) Ghildyal, N. P., B. K. Lonsane and N. G. Karanth: Adv. Appl. Microbiol., 33, 173 (1988).

3) Hall, M. J., S. D. Dickinson, R. Pritcard and J. I. Evans: Prog. Ind. Microbiol., 12, 170 (1973).

4) Ohkawa, A., O. Matsubara, N. Sakai and K. Endoh: J. Chem. Eng. Japan, 20, 94 (1987)

5) Yasukawa, M., M. Onodera, K. Yamagiwa and A. Ohkawa: J. Chem. Eng. Japan, 24, 188 (1991).

6) Viesturs, U. E., M. Z. Kristasons and E. S. Levitans: $A d v$. Biochem. Eng., 21, 169 (1982). 